\title{
Reuse \& Recirculation of Filter Backwash Water of Water Treatment Water
}

\author{
Mangesh L. Jibhakate*, M. P. Bhorkar**, A. G. Bhole***, P. K. Baitule**** \\ *(M. Tech. Scholar, Department of Civil Engg., GHRCE, Ngpurl6 \\ Email: jibhkate_mangesh.ghrcemtechenv@raisoni.net) \\ ** (assistant Professor, Department of Civil Engg., GHRCE, Ngpurl6 \\ Email:mangesh.bhorkar@gmail.com) \\ ***(Ex-Professor, Civil Engg. Dept., VNIT, Nagpur) \\ ****(Lecturer, KDK, NPN Polytechnic, Nagpur 24 \\ Email: payal.baitule14@gmail.com)
}

\begin{abstract}
Most of the water treatment plant, filtration is done by means of sand filtration process. Due to continuous filtration process, sand pores get clogged and decreases the efficiency. For mitigating such problem, reverse flow of water \& air i.e. backwashing process is carried out. To carry out backwashing operation, $4 \%$ of treated water has been utilized and will result in muddy water known as backwash water. This backwash water is then discharged into a natural stream or storage tank near the plant for recirculation. The present study includes a trial
\end{abstract} for the reuse \& recirculation of backwash water.

Keywords: Backwash water, Filtration, Reuse \& Recirculation

\section{INTRODUCTION}

Filtration is one of the most important \& essential process of water treatment. In this process, water allows passing through sand filter media and then collects in the storage tank followed by disinfection process. This process helps to remove impurities present in the water like suspended colloidal particles which don't trapped in the sedimentation process. At certain interval of time, sand pores may get clogged due to fine colloidal particles and decreases the efficiency of filter bed. And hence it is needed to remove these fine particles from the pores of the sand. The well known process for removal of these fine particles is filter backwashing.

Filter backwash is the process in which $4 \%$ of treated water is kept aside for backwashing. This amount of treated water is then allowed to flow through the bed in reverse direction i.e. upward flow. The duration required for backwashing with treated water is 15 to 20 minutes with additional flow of air. Air helps to make sand free from fine clogged particles. This process is carried out when the head loss is more and efficiency becomes less. In rainy season backwashing is to be carried out frequently because turbidity in surface water is more in those days.

Usually, backwash water discharges into a natural stream by most of the WTPs. Some of them believes on zero discharge and try to store within the premises for further recirculation. It helps to minimize the raw water demand as well as prevents the natural stream from high sedimentation. In this study, an approach is done towards the recirculation and reuse of backwash water. For the reuse \& recirculation of backwash water, a setup is installed at a water treatment plant located at Nagpur, Maharshtra.

\section{LITERATURE REVIEW}

Joachim Backhaus el at. (2001) In this paper the focus is carried out on many supply sources of drinking water which contains objectionable substances. In order to remove these impurities for safe human consumption certain approach was done by researcher. In filtration unit, frequently used filters are to be washed out in the system frequently. This backwashing process requires up to $3 \%$ of the fresh volume of water which is then disposed into wastewater. In this study it is demonstrated that, the feasibility and potential for optimizing the membrane process, resulting in the high filtrate quality and economical viability also. In this plant $99.9 \%$ of the backwash water is re-circulated and is used as drinking water.

\section{B.M. Brouckaert et al. (2003)}

In this paper the advantages \& disadvantages of some backwashing systems are discussed. The use of slow sand filters which is always advantageous because it doesn't requires backwashing. And in case of Rapid sand filters which requires backwashing frequently. The mud 
balls are been formed in the filters if coarser media is used in this unit. The removal of mud balls can be possible when they form or can be break up. Upon use of Auxiliary wash to filters it is not necessary to clean the filters in a year or two. Or a possible solution incorporated is to replace the upper layer of filter. An approach was done by the author to increase the life of filter.

Sagar Suman et al. (2012) In this paper water treatment plant arises the problem of clogging of sand granular gravel media filters due to increase passage between particles \& microorganism. To avoid such problem there is need of backwashing and these results in to loss of water. In most water treatment plant filter backwash water (FBWW) and clarified sludge water (CSW) are generated. The recycling of filter backwash water (FBWW) and clarified sludge water are generated. The recycling of filter backwash water (FBWW) and it give suitable treatment is possible in order to provide good quality of water quantity. The experiments performed with raw water (RW) and filter backwash water (FBWW) at Bhagirathi water treatment plant. The removal of dissolve organic carbon and total organic carbon was examined by filter backwash water $5-10 \%$ with raw water. The result indicated by jar test for improvements in raw water quality is observed by recycling of FBWW with RW.

Ishwar P. Patil et al. (2013) In this paper the recycling of water is very important for life and then various treating technologies is used. These is most used for irrigation and various purposes to be used for industry level plant. In the recycle of the water to be purify then, it will be reused to the site of the project and in the same system for the municipal of water is also used for the recycling processes and this recycle of water is used in agriculture used and to checking the mechanism of the system of each unit. The turbidity is more then, it will use for irrigation purposes and normal range of turbidity then, to use manmade. In the greater amount of processes the purifying the water and daily uses this water is very important. The various advance technique of treating mechanism is used for this project and to the various scheme for water storage is important in the field. These are best way to be recycling processes and reuse of water for continuous system.

Hanan A. Fouad at el. (2016) In this paper re-use filter backwash water (FBWW) by introducing with raw water in the purification plant. About 10-15\% water generated among purified water. The mixing ratio taken as $40 \%$ filter backwash water (FBWW) $\& 60 \%$ raw water. The main objective calculated the feasibility of reuse filter backwash water (FBWW) introducing from the effluent filter backwash pipe of El-Giza water treatment plant(WTP). In water treatment plant available 48 rapid sand filter and for backwashing total water use $10 \%-15 \%$ pump to the water treatment plant (WTP). Raw water and filter backwash water $10-50 \%$ of mixing ratio.

L. Delgado et al. ( 2004) In the water of new source is reclamation of water by reducing the phenomena of material. For the ground level of water to be converting a greater flow of demand of energy i.e. the desalination of water is formed. It is useful for the decreasing level of pollution of water from the raw water outflow in the system and to improve the system of environmental reason. To these waste water recycle and then reuse to the one place to another for various purposes to be used. In that case modified country to be a low prize of commonly usable of the phenomena and there are greater technologies is use for a modified system to the more energy is usable for these purpose. In these wastewater to be treating purpose technology is to be used.

\section{MATERIAL \& METHODOLY}

This study involves the reuse $\&$ recirculation of backwash water of a Water Treatment Plant by fabrication a pilot scale unit at plant. The backwash water is stored in the sump which is within the premises of WTP and then usually re-circulated to aeration unit. But this process again increases the load on the treatment units after aeration. The study is an approach to treat the backwash water \& recirculated through aeration unit. This will helps to minimize the load on further units.

The fabricated unit includes

\begin{tabular}{|c|c|c|c|}
\hline $\begin{array}{c}\text { Sr. } \\
\text { No. }\end{array}$ & \multicolumn{1}{|c|}{ Unit } & Quantity & Capacity \\
\hline 1 & Plastic Tank & 2 & 200 litre \\
\hline 2 & Plastic Tank & 2 & 300 litre \\
\hline 3 & Flocculator & 1 & $\begin{array}{c}\text { Equipped with } \\
\text { 4 blades }\end{array}$ \\
\hline
\end{tabular}

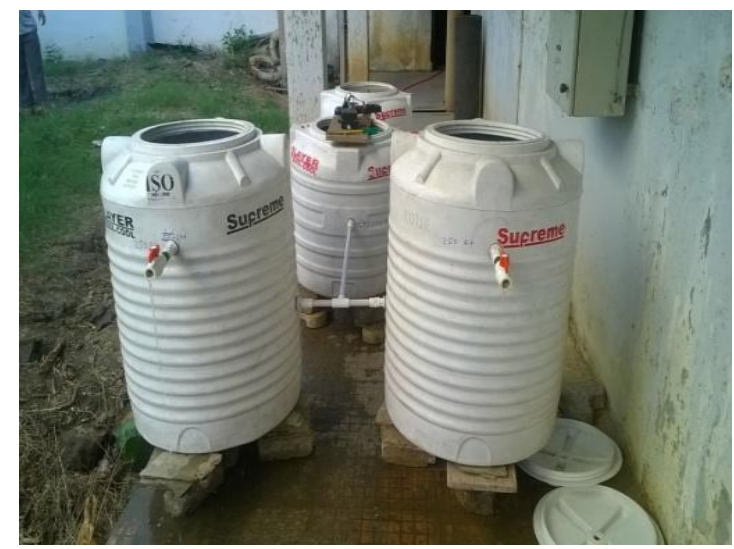

Fig. Setup for Backwash water treatment 
The process of treatment includes collection of backwash in storage tank (plastic tank 1), then the water goes to next unit i.e. flocculation tank where PAC (poly aluminum chloride) dosing is done \& flocculator is operated at $5 \mathrm{rpm}$ for flocculation process. The detention time designed for this process 30 minutes for the flocculation. Then water allows to flow in next tank i.e. sedimentation tank (Plastic Tank 3 \& 4, 600 liter capacity). Detention time in this unit is 2 to 2.5 hours. This allows the flocculated particles to settle down and the influent (clear water) is collected \& transferred to the aeration tank. The flow rate was kept as 10 $1 \mathrm{tr} / \mathrm{min}$ (Description is as below).

Calculation for Rate of flow:

$\mathrm{DT}=\mathrm{V} / \mathrm{Q}$

Where, DT $=$ Detention time (20 Minutes)

$\mathrm{V}=$ Volume of tank (200 ltr)

So, $20=200 / \mathrm{Q}$

$\mathrm{Q}=$ Discharge $\left(\mathrm{m}^{3} / \mathrm{Min}\right)$

Rate of flow $(\mathrm{Q})=10$ lit $/ \mathrm{min}$

The analysis of the parameters like $\mathrm{pH}$, turbidity, conductivity, TDS, alkalinity, temperature has been carried out for the raw water and filter backwash water. Analysis of treated water is also carried out for same parameter but focus was only on turbidity of backwash water. The study also includes the comparison of raw \& treated water.

\section{RESULT \& DISCUSSION}

The setup has given good efficiency in removal of turbidity form the backwash water. The results obtained for backwash water, flocculated water \& treated water from the study are shown in graphical form-

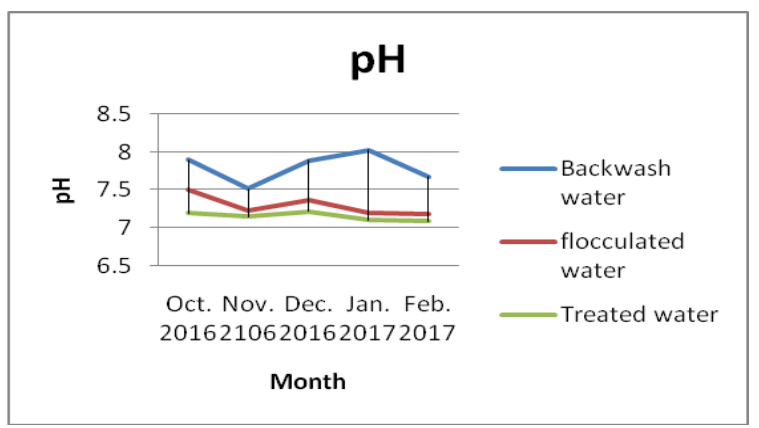

Fig: $\mathrm{pH}$ values for rainy and winter season

In rainy season backwash water $\mathrm{pH}$ was 7.8 and in winter season $\mathrm{pH}$ were 8.2. Wherein in rainy season $\mathrm{pH}$ for flocculated water was 7.5 and in winter season it was 7.3. Finally in rainy season the $\mathrm{pH}$ of treated water was obtained as 7.3 and in winter season $\mathrm{pH}$ was 7.2. The $\mathrm{pH}$ value after treatment was very near to neutral state.

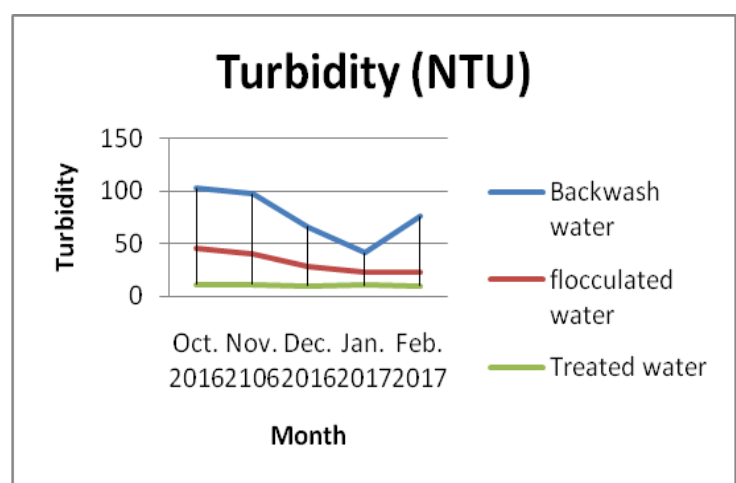

Fig: Turbidity values for rainy and winter season for backwash \& treated water

In rainy season turbidity of backwash water is $102 \mathrm{NTU}$ and in winter season turbidity is 42 NTU and for treated water in rainy season turbidity is $11 \mathrm{NTU}$ and winter season turbidity is 7 NTU.

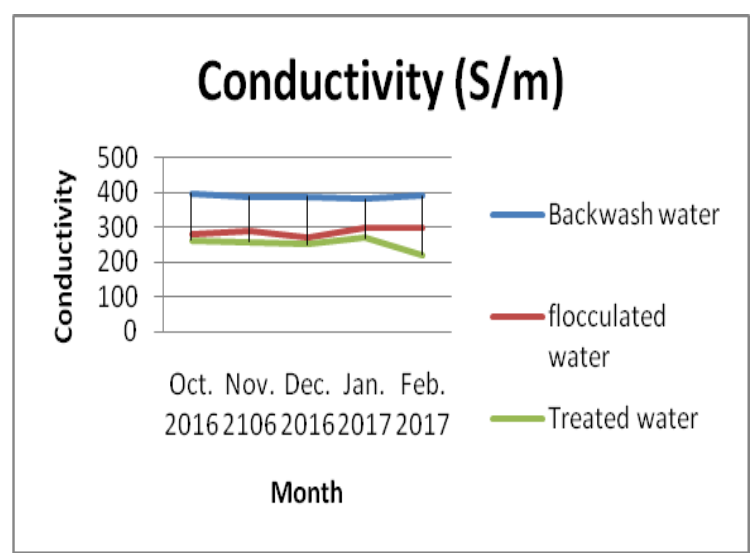

Fig: Conductivity values for rainy and winter season

In rainy season in backwash water Conductivity is $400 \mathrm{~S} / \mathrm{m}$ and in winter season Conductivity is 375 $\mathrm{S} / \mathrm{m}$ in treated water (rainy season) Conductivity is $260 \mathrm{~S} / \mathrm{m}$ and winter season Conductivity is $270 \mathrm{~S} / \mathrm{m}$.

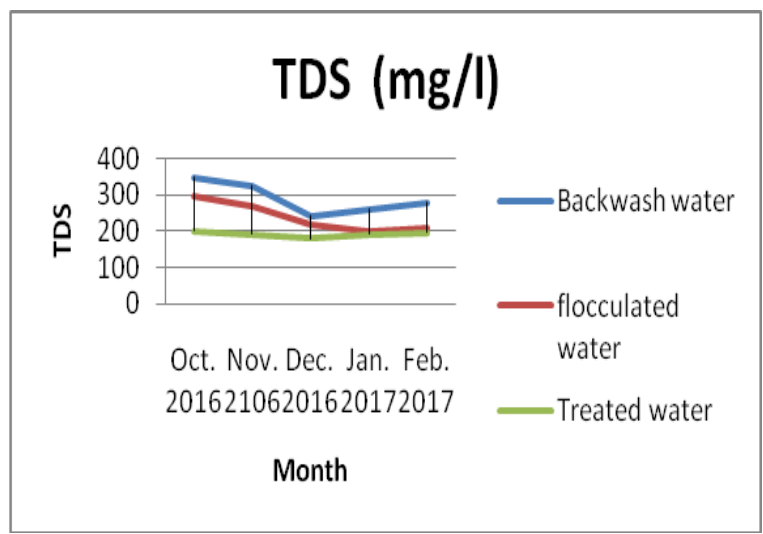

Fig: TDS values for rainy and winter season for backwash \& treated water

In rainy season in backwash water TDS is more i.e $350 \mathrm{mg} / \mathrm{l}$ and for winter season TDS is $265 \mathrm{mg} / \mathrm{l}$ and 
in treated water in rainy season TDS is $201 \mathrm{mg} / \mathrm{l}$ and winter season TDS is $190 \mathrm{mg} / \mathrm{l}$.

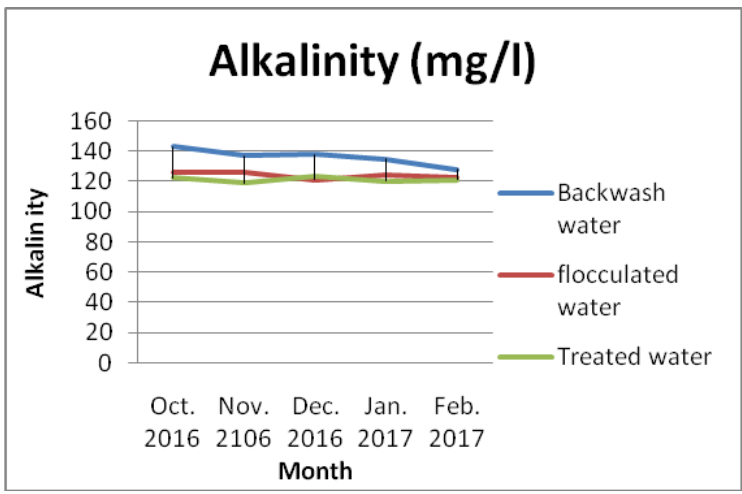

Fig: Alkalinity values for rainy and winter season

In Backwash water parameter (rainy season) have Alkalinity is $149 \mathrm{mg} / \mathrm{l}$ and winter season Alkalinity is $135 \mathrm{mg} / \mathrm{l}$ and Flocculated water (rainy season) have Alkalinity is $129 \mathrm{mg} / \mathrm{l}$ and winter season $127 \mathrm{mg} / \mathrm{l}$ and last is treated water (rainy season) Alkalinity is $122 \mathrm{mg} / \mathrm{l}$ and winter season Alkalinity is $120 \mathrm{mg} / \mathrm{l}$.

\section{CONCLUSION}

Form the above study it is concluded that, the backwash water can be reuse \& recirculated with minimum turbidity which will reduce the load on further treatment unit. Again it will lead to zero discharge concept \& can save $4 \%$ of treated water within the plant only.

\section{Journal Papers:}

\section{REFERENCES}

[1]. Hanan A. Rehab, M. El-Hefny, Mahetab Ali Mohamed, Reuse of spent filter Backwash water International Journal of civil Engineering \& Technology (IJCIET), JulyAugust 2016

[2]. Sravanthi Animireddy1, M.P Sharma, Automation of common effluent treatment plant, International Journal of Advanced Technology in Engineering and Science, Volume No.03, Issue No. 02, February 2015 ISSN.

[3]. Ishwar P. Patil1, Prof. Hemant D. Wagh and Prof.(Dr.) Arun Kumar Dwivedi, Water Recycle and Reuse "C A Case Study of NMIMS University Campus, International Journal of Engineering Science Invention, Volume 2 Issue, September 2013.

[4]. Sagar Suman, Singh N.P., Chandra Sulekh, Effect of Filter Backwash Water when blends with Raw Water on Total Organic Carbon and Dissolve Organic Carbon Removal, Vol. 2(10), October (2012)
[5]. C.I.M. Martinsa, b, E.H. Edinga, M.C.J. Verdegema, L.T.N. Heinsbroeka, O. Schneiderc, J.P. Blanchetond, E. Roque Orbcasteld and J.A.J. Verretha, New developments in recalculating aquaculture systems in Europe: A perspective on environmental sustainability, November 2010

[6]. Dr. R. K. Sivanappan, Rain Water Harvesting, Conservation and Management Strategies for Urban and Rural Sectors, National Seminar on Rainwater Harvesting and Water Management 11-12 Nov. 2006, Nagpur.

[7]. B.M. Brouckaert, A. Amirtharajah, R. Rajagopaul. P. Thompson, Filter backwash options for rural treatment plant, School of Chemical Engineering, Pollution Research Group, University of KwaZulu-Natal.

[8]. L. Delgado, Y. Poussade and A. Romero, Comparative Study of the Operational Carbon Footprint of Water Reclamation, Barcelona Metropolitan Area, Environmental Authority (AMB) c/ 62, 16-18, Zona Franca, 08040,Barcelona, Spain. 